\title{
Sustentação do emprego e renda na crise econômica da Covid- 19 em países da América Latina
}

\author{
Supporting employment and income in the Covid-19 economic crisis in Latin \\ American countries
}

\author{
Rosa Maria MARQUES ${ }^{*}$ \\ https://orcid.org/o0oo-0002-5624-0885 \\ Solange BERWIG** \\ https://orcid.org/oooo-0002-6964-044X \\ Marcelo DEPIERI*** \\ http://orcid.org/oooo-0oo2-2175-2098?lang=en \\ Marcel Guedes LEITE $E^{* * *}$ \\ htpps://orcid.org/oooo-0001-9305-9703
}

Resumo: Este artigo aborda ações desenvolvidas para o enfrentamento da crise econômica decorrente da Covid-19 em cinco países da América Latina: Brasil, Argentina, Uruguai, Peru e México. A fonte de coleta e análise foi formada de documentos de domínio público, com informações sobre o cenário nos países desde a entrada da Covid-19, de março a agosto de 2020. O texto está organizado em dois eixos centrais: 1) as medidas de sustentação do emprego e 2) as ações de sustentação da renda. A análise revelou que nem todos os países criaram instrumentos novos, preferindo utilizar a estrutura e os programas já existentes. Também os países se diferenciaram no tocante ao financiamento das ações. Embora essas não tenham conseguido impedir a deterioração do mercado de trabalho e da renda dos ocupados, foram fundamentais na mitigação do impacto da crise.

Palavras-chave: Sustentação do emprego. Sustentação de renda. Covid-19. América Latina.

Abstract: This article discusses actions developed to confront the economic crisis resulting from Covid19 in five Latin American countries: Brazil, Argentina, Uruguay, Peru, and Mexico. The source of data and analysis was from documents in the public domain containing information about the situation in these countries since the beginning of Covid-19, from March to August 2020. The text is organized along

\footnotetext{
${ }^{1}$ Este estudo é fruto de uma pesquisa realizada em parceria com professores da Pontifícia Universidade Católica de São Paulo (PUC-SP), Universidade Paulista (UNIP) e Universidade Federal do Pampa (UNIPAMPA).

* Economista. Doutorado em Economia. Professora titular de economia da Pontifícia Universidade Católica de São Paulo (PUCSP, São Paulo, Brasil). R. Monte Alegre, 984, Perdizes, São Paulo (SP), CEP.: 05014-901. E-mail: rosamkmarques@gmail.com.

${ }^{* *}$ Assistente Social. Doutorado em Serviço Social. Professora adjunta de Serviço Social da Universidade Federal do Pampa. (Unipampa, São Borja, Brasil). Rua Ver. Alberto Benevenuto, 320o, Passo, São Borja, RS, CEP.: 97670-ooo. E-mail: solangeberwig@unipampa.edu.br.

*** Economista. Doutorado em Ciências Sociais. Professor titular de economia da Universidade Paulista. (Unip, São Paulo, Brasil). Av. Marquês de São Vicente, 30o1, mezanino, sala dos professores, Água Branca, São Paulo (SP), CEP.:05037-040. E-mail: cellodepieri@gmail.com.

**** Economista. Doutorado em Economia de Empresas. Professor Assistente Doutor da Pontifícia Universidade Católica de São Paulo (PUCSP, São Paulo, Brasil). R. Monte Alegre, 984, Perdizes, São Paulo (SP), CEP.: 05014-901. E-mail: magle@uol.com.br.
}

Argum., Vitória, v. 12, n. 3, p. 308-332, set./dez. 2020. | ISSN 2176-9575 
two central axes: 1) measures to support employment and 2) actions to support income. The analysis reveals that not all countries have created new instruments, preferring to use existing structures and programs. Countries also differ in terms of financing actions. Although these failed to prevent the deterioration of the labor market and the income of the employed, they were instrumental in mitigating the impact of the crisis.

Keywords: Employment support. Income support. Covid-19. Latin America.

Submetido em: 2/9/2020. Revisado em:3/11/2020. Aceito em: 3/11/2020.

\section{Introdução}

profundidade da crise econômica provocada pela Covid-19 não tem precedente
na história recente do capitalismo. Ela passará à história econômica como a
crise da Covid-19. As últimas estimativas do Fundo Monetário Internacional (INTERNATIONAL MONETARY FUND, 2020), de junho, previam, para 2020, uma queda $4,9 \%$ da economia mundial e de 9,4\% para a região da América Latina e Caribe (AL). Já o Banco Mundial (WORLD BANK, 2020), também em junho, estimava uma retração de $5,2 \%$ para a economia mundial e de $7,2 \%$ para a AL. Um mês depois, a Comissão Econômica para a América Latina e o Caribe (CEPAL, 2020) divulgou previsões de quedas de $5,2 \%$ e de $9,1 \%$, respectivamente. Essa crise se distingue da ocorrida em 2007/2008 tanto por sua magnitude como por seu elemento detonador: um elemento externo que atuou como se alguém desligasse, de repente, a energia que alimentava as economias. Embora a economia mundial nunca tivesse, a rigor, se recuperado da crise anterior, a queda do PIB de 2020 não foi provocada por constrangimentos que já estavam presentes; esses constituíram o pano de fundo sobre o qual se estabeleceu a recessão provocada pelo necessário isolamento social para fazer frente à pandemia. Em alguns países, esse quadro anterior foi determinante na definição dos instrumentos de financiamento das medidas adotadas pelos governantes. Pari passu à paralisação das atividades econômicas, o desemprego assumiu níveis muito altos, deixando a descoberto, em termos de renda, não só os segmentos já vulneráveis, como parte dos que tinham emprego e renda garantidos, fossem eles trabalhadores assalariados ou proprietários e sócios de pequenas e médias empresas.

Em março, quando a Organização Mundial da Saúde (OMS) considerou que o mundo enfrentava uma pandemia, diversas agências, recomendaram que, entre outras sugestões, os Estados assumissem as perdas decorrentes da crise, isto é, atuassem como empregador de última instância. Afora enfrentar adequadamente a questão sanitária, a preocupação era minimizar ao máximo a perda de renda, manter a liquidez na economia, criar mecanismos de apoio ao emprego, proteger as cadeias de pagamento e simplificar a reestruturação da dívida dos países. Daí decorriam recomendações que visavam proteger indivíduos, famílias e empresas, que sugeriam a flexibilização de regras e dispositivos e a adoção de novas políticas. De maneira geral, governos de distintas orientações políticas acabaram por implantar medidas que tinham como propósito mitigar a crise.

Marques e Depieri (no prelo), ao analisarem o banco de dados das agências com relação às medidas adotadas pelos países, destacam que elas são agrupadas em duas categorias: políticas fiscais e monetárias; e políticas de emprego e social. Entre o leque de medidas que foram assumidas pelos países, analisamos, neste artigo, as relacionadas 
à sustentação do emprego e renda dos ocupados, estivessem eles no mercado formal ou informal antes do início da crise. No que se refere ao emprego, tratamos de levantar se foram acompanhadas por redução de salário e alteração no contrato entre o empregador e o trabalhador; se elas consideravam (consideram) algum critério que envolvesse o tamanho das empresas e setores de atividades, bem como o financiamento das medidas e o tempo de sua duração. No caso das políticas que podem ser classificadas como de transferência de renda e de sua sustentação, a preocupação foi levantar, além dos critérios de acesso, do valor pago, da duração do benefício e seu financiamento, se a medida complementava políticas pré-existentes, somando-se a elas, ou se constituía numa política nova.

Para o estudo, foram escolhidos cinco países: Brasil, Argentina, Uruguai, México e Peru, mesclando critérios econômicos, sociais e políticos. Com exceção do Peru, os demais têm presidentes que se viram frente à crise da Covid-19 em seu primeiro ano de mandato, ou um pouco mais do que isso. Brasil, Argentina, Uruguai e México têm presidentes de orientação política diametralmente oposta à de seus antecessores, de modo que suas ascensões presidenciais são vistas como ruptura de processos anteriores. No caso do Brasil, embora a política econômica do atual presidente (Jair Bolsonaro) não se diferencie da conduzida pelo presidente anterior (Michel Temer que assumiu o governo quando do impeachment de Dilma Rousseff), sua orientação política situa-se no campo da ultradireita, podendo, portanto, sua eleição ser entendida como uma alteração radical no ambiente no país. Nesse quadro, novamente o Peru constitui uma exceção, dado que o atual presidente, Martin Vizcarra, que assumiu em 2018, é do mesmo partido do antecessor.

Todos países analisados, afora o Uruguai, possuem taxas altas de informalidade, chegando a representar 72,7\% dos ocupados no Peru. Quanto à situação econômica, ganha importância analisar como a Argentina deu conta de enfrentar a questão da sustentação do emprego e da renda convivendo com as sérias restrições advindas da crise da dívida externa que chegou a 93\% do PIB em 2019. No Brasil, o mesmo se coloca, dado que, desde 2017, estava vigente o congelamento do gasto do governo federal. Já quanto ao Peru, a relação dívida/PIB, em 2019, foi de 26,8\%, uma das menores da América Latina. O país, inclusive, foi lembrado pelos organismos internacionais como sendo exemplo no manejo das políticas econômicas. Em janeiro de 2019, os diretores do FMI elogiaram o Peru pela "[...] larga trajetória de políticas econômicas prudentes” (FUNDO MONETÁRIO INTERNACIONAL, 2020, não paginado). O Banco Mundial, por sua vez, já no contexto da pandemia, em relatório de abril/2020, afirmou que "[...] a prudente gestão macroeconômica do país [...]" (BANCO MUNDIAL, 2020, p. 63) proporcionaria melhores condições para as medidas fiscais e monetárias necessárias para mitigar os efeitos da crise. Segundo a Cepal (2020), esses países terão uma retração no seu PIB, em 2020 de 13\% (Peru), 10,5\% (Argentina), 9, 2\% (Brasil), 9,0\% (México) e 5,0\% (Uruguai). É possível que esses percentuais sejam menores, pois medidas implantadas foram prorrogadas e, assim, garantiram parte da renda da população.

O levantamento das informações foi realizado com base em quatro fontes: bancos de dados oficiais dos países escolhidos; relatórios do FMI, BM, Organização para a 
Cooperação e Desenvolvimento Econômico (OCDE) e Cepal; documentos oficiais legislações, decretos, programas; e, notícias de jornais e revistas editados nos países pesquisados. O texto está organizado em duas partes, além dessa introdução e das considerações finais. A primeira é dedicada às medidas de sustentação do emprego, quando são apresentadas e analisadas as medidas tomadas em cada país; a segunda é voltada às medidas de transferência de renda.

\section{Políticas de sustentação do emprego}

No Brasil, no momento em que o primeiro caso do novo coronavírus foi detectado (26/02), a taxa de desemprego do trimestre encerrado em fevereiro era de 11,6\%, atingindo 12,3 milhões de trabalhadores e $46 \%$ das pessoas ocupadas estavam na informalidade (INSTITUTO BRASILEIRO DE GEOGRAFIA E ESTATÍSTICA, 2020a). $\mathrm{Ou}$ seja, foi sobre um mercado de trabalho altamente precarizado que a crise econômica advinda da pandemia atuou.

As iniciativas realizadas pelo governo federal para combater o avanço do desemprego em função da recessão provocada pelo isolamento social confundem-se, em parte, com as medidas de manutenção da renda. Essas últimas são tratadas à parte, no próximo tópico. Em relação ao emprego, as medidas entendidas enquanto ações diretas de sua sustentação, dizem respeito a: 1) o Programa Emergencial de Manutenção do Emprego e da Renda, em vigor desde março de 2020, e sancionado na Lei Federal no $\mathbf{1 4 . 0 2 0}$ em 06/o7 (BRASIL, 2020d); 2) criação, em abril, de linha de crédito para pequenas e médias empresas para pagamento de salários (MP 944).

O Programa Emergencial visa a manutenção dos postos de trabalho, prevendo redução da jornada de trabalho e salário (por até 90 dias) ou suspensão do contrato (por 6o dias), sendo que, em 14/o7, a redução foi prorrogada por um mês e a suspensão por dois meses. O salário pago pelo empregador em caso de redução da jornada é complementado pelo Benefício Emergencial de Preservação do Emprego e da Renda. O valor do benefício é calculado aplicando-se o percentual de redução do salário ao que o/a trabalhador/a teria direito se requeresse o seguro desemprego. Ou seja, se o trabalhador tiver a jornada e salário reduzidos em $50 \%$, seu benefício será de $50 \%$ do valor do seguro desemprego ao qual teria direito, se tivesse sido dispensado. A Confederação Nacional dos Trabalhadores nas Empresas de Crédito (CONFEDERAÇÃO NACIONAL DOS TRABALHADORES NAS EMPRESAS DE CRÉDITO, 2020) simulou como ficaria a recomposição dos salários dos trabalhadores de acordo com seu nível (Tabela 1). Na tabela se pode ver que a única situação em que não há perda de renda, não importando o tamanho da redução do salário, é quando o trabalhador recebe um salário mínimo. Isso decorre do fato de que nenhum benefício pago pode ser menor do que o salário mínimo, tal como dispõe a constituição brasileira. Dessa forma, quanto maior o salário e maior a redução decorrente da diminuição da jornada de trabalho, maior é a perda de renda do trabalhador, mesmo ele recebendo o benefício compensatório.

A Secretaria Especial de Previdência e Trabalho (SEPRT), do Ministério da Economia informou, em 29/o6, que 11.698.243 empregos foram preservados mediante esse 
Programa, fruto de acordos firmados por 1.348.733 estabelecimentos. Desses acordos, de abril a junho, 5.423.172 foram de suspensão de contrato de trabalho; 1.706.748 de redução de 25\% do salário; 2.144.886, de redução de 50\%; 2.256.368, de 70\% e 167.069 relativos a trabalho intermitente. Um pouco mais da metade, 50,4\% (5.899.841) foi firmado com micro e pequenas empresas, com faturamento anual abaixo de $\mathrm{R} \$ 4,8$ milhões. Quanto ao setor de atividade, destacam-se o de serviços, com 5.353.412 acordos, seguido pelo comércio (2.966.199), indústria (2.758.327) e construção civil (299.019). Entre os estados, destacam-se: São Paulo (3.810.012), Rio de Janeiro (1.135.735) e Minas Gerais (1.051.952) (PROGRAMA..., 2020).

Tabela 1 - Simulação da recomposição dos salários

\begin{tabular}{|c|c|c|c|c|c|c|c|c|}
\hline Salário & $\begin{array}{l}\text { Hipóteses } \\
\text { redução }\end{array}$ & $\begin{array}{l}\text { Valor da } \\
\text { redução }\end{array}$ & $\begin{array}{l}\text { Salário com } \\
\text { redução }\end{array}$ & $\begin{array}{c}\text { Valor do } \\
\text { Seguro- } \\
\text { desemprego }\end{array}$ & \begin{tabular}{|c|} 
Valor de \\
compensação \\
proposto
\end{tabular} & $\begin{array}{c}\text { Salário + } \\
\text { compensação }\end{array}$ & Perdas & $\%$ \\
\hline \multicolumn{9}{|c|}{1 Salário Mínimo } \\
\hline \multirow{3}{*}{$1.045,00$} & $25 \%$ & 261,25 & 783,75 & 1045,00 & 261,25 & 1045,00 & 0 & 0 \\
\hline & $50 \%$ & 522,50 & 522,25 & 1045,00 & 523,00 & 1045,00 & 0 & 0 \\
\hline & $70 \%$ & 731,50 & 313,50 & 1045,00 & 731,50 & 1045,00 & 0 & 0 \\
\hline \multicolumn{9}{|c|}{ 2 Salários Mínimos } \\
\hline \multirow{3}{*}{$2.090,00$} & $25 \%$ & 522,50 & $1.567,50$ & $1.524,89$ & 381,22 & $1.948,72$ & $-141,28$ & 6,76 \\
\hline & $50 \%$ & $1.045,00$ & $1.045,00$ & $1.524,89$ & 762,45 & $1.807,45$ & $-282,56$ & 13,52 \\
\hline & $70 \%$ & $1.463,00$ & 627,00 & $1.524,89$ & $1.067,42$ & $1.694,42$ & $-395,58$ & 18,93 \\
\hline \multicolumn{9}{|c|}{ Média salarial do Brasil - 2.234,00 (base 2019) } \\
\hline \multirow{3}{*}{$2.234,00$} & $25 \%$ & 558,5 & $1.657,50$ & $1.956,89$ & 399,22 & $2.074,72$ & 159,28 & $-7,13$ \\
\hline & $50 \%$ & $1.117,00$ & $1.117,00$ & $1.956,89$ & 798,44 & $1.915,44$ & 318,56 & $-14,26$ \\
\hline & $70 \%$ & $1.563,80$ & 670,20 & $1.956,89$ & $1.117,82$ & $1.788,02$ & 445,02 & $-19,96$ \\
\hline \multicolumn{9}{|c|}{5 Salários Mínimos } \\
\hline \multirow{3}{*}{$5.225,00$} & $25 \%$ & $1.306,00$ & $3.918,75$ & $1.813,03$ & 399,22 & $4.317,97$ & 907,03 & $-17,36$ \\
\hline & $50 \%$ & $2.612,50$ & $2.612,50$ & $1.813,03$ & 798,44 & $3.410,94$ & $1.814,06$ & $-34,72$ \\
\hline & $70 \%$ & $3.657,50$ & $1.567,50$ & $1.813,03$ & $1.117,82$ & $2.685,32$ & $2.539,68$ & $-48,61$ \\
\hline
\end{tabular}

Fonte: Confederação Nacional dos Trabalhadores nas Empresas de Crédito. Adaptado (2020)

Por sua vez, a linha de crédito dirigida às pequenas e médias empresas (com faturamento entre R\$36o mil e R\$ 10 milhões por ano), iniciada em o6/o4, tem como objetivo financiar até dois salários mínimos por trabalhador, sob a condição de que as empresas não demitam seus funcionários durante dois meses. A taxa de juros do empréstimo é de 3,75\%aa, com carência de seis meses e um prazo de 30 meses para o pagamento do empréstimo. Os salários são pagos diretamente aos trabalhadores, sem intermediação do empregador. Essa linha de crédito, no total de R\$ 40 bilhões, é financiada pelo Tesouro Nacional (R\$ 34 bilhões) e pelos bancos privados (R\$ 6 bilhões). Em 15/o5, segundo o jornal Gazeta do Povo (SANT'ANA, 2020), apenas 3,5\% dos recursos disponíveis haviam sido utilizados, num total de 61.567 empresas e beneficiando 1.032.477 trabalhadores. Ao final de maio, esse percentual havia aumentado para 4,9\%, de acordo com o relatório da Confederação Nacional do Transporte (CNT) (2020), e a medida era considerada um fracasso.

O resultado dessas iniciativas não impediu que o desemprego se aprofundasse no país e que a precarização do trabalho aumentasse. Em maio, $55,5 \%$ das pessoas com idade para trabalhar estavam desocupadas, registrando o pior desempenho desde o início do levantamento em 2012. Nesse mês, em relação a fevereiro, houve aumento de cinco pontos percentuais nesse percentual (INSTITUTO BRASILEIRO DE GEOGRAFIA E ESTATÍSTICA, 202ob). Por sua vez o desemprego atingiu 12,9\%. Na verdade, essa taxa 
deixou de captar adequadamente a realidade do trabalhador, tal o tamanho do segmento que deixou de procurar emprego pois as oportunidades simplesmente tenderam a desaparecer. Sobre a situação do mercado de trabalho, assim se manifestou o Departamento Intersindical de Estatística e Estudos Econômicos (DIEESE) (2020).

\begin{abstract}
Em maio, 26,3 milhões de brasileiros declararam não ter trabalhado nem procurado trabalho, mas que gostariam de estar trabalhando. Entre eles, 18,5 milhões afirmaram estar nessa situação por causa da pandemia. Do total de ocupados, 19,0 milhões estavam afastados do trabalho. Desses, 15,7 milhões disseram que o motivo do afastamento era a pandemia e 9,7 milhões relataram ter deixado de receber remuneração. Cerca de $36 \%$ dos trabalhadores ocupados em maio (30 milhões de pessoas) tiveram alguma perda no rendimento na comparação com a situação anterior à pandemia. A redução média do rendimento foi de $61 \%$ (DEPARTAMENTO INTERSINDICAL DE ESTATÍSTICA E ESTUDOS ECONÔMICOS, 2020, p. 4).
\end{abstract}

O DIEESE enfatiza, ainda, como seria de esperar, que as consequências do isolamento social e da pandemia foi maior entre os trabalhadores informais, "[...] mais da metade (56\%) teve perda de rendimento. Entre os formais, $26 \%$ apresentaram redução da Renda” (DEPARTAMENTO INTERSINDICAL DE ESTATÍSTICA E ESTUDOS ECONÔMICOS, 2020, p. 4). A renda dos trabalhadores informais caiu 36\%; já para os trabalhadores com carteira assinada $12 \%$. Entre os trabalhadores que continuaram suas atividades laborais, e que perderam renda, pelo menos metade recebeu o benefício do auxílio emergencial, que é tratado no item sobre as políticas de sustentação de renda.

No caso da Argentina, é relevante observar seu longo histórico de instabilidade política e econômica. Entre outros motivos, a situação política do país é considerada instável pela alternância entre governos de direita e esquerda. Mais recentemente, houve perda de credibilidade do país durante a gestão do governo Macri, que implicou consequências econômicas e uma situação social de grande tensão entre o governo e os movimentos sindicais e sociais, especialmente em relação às reformas anunciadas Reforma da Previdência e Reforma Trabalhista ${ }^{2}$ (SANTANDER, 2020). Quando da chegada da pandemia no país (03/2020), a Argentina registrava uma taxa de desemprego de 10,4\% (fechamento no primeiro trimestre de 2020 ), e os trabalhadores não registrados - informais, e os identificados como independentes, representam $49 \%$ de sua estrutura trabalhista (INSTITUTO NACIONAL DE ESTATÍSTICA E CENSOS, 2020). O Ministério do Trabalho, Emprego e Seguridade Social argentino tem monitorado as alterações das condições de trabalho formal no país,

[...] as informações que emergem da Pesquisa de Indicadores do Trabalho (EIL) de abril e do Sistema Integrado de Seguridade Social da Argentina (SIPA) de março refletem claramente o impacto da pandemia no trabalho registrado, interrompendo a recuperação incipiente que havia sido vislumbrada em fevereiro. Ambas as fontes de informação mostram que o trabalho registrado contraiu na maioria de suas formas, incluindo o emprego assalariado em empresas privadas. Isso é verificado em um contexto em que,

\footnotetext{
${ }_{2}^{2}$ As propostas foram amplamente rechaçadas pela população, especialmente pela classe trabalhadora, que protagonizou um grande movimento. A Reforma da Previdência foi aprovada em 2017, mas a da reforma laboral não foi levada adiante. A posição do governo Macri teve impacto no processo eleitoral, em que a população optou pelo retorno ao peronismo elegendo a chapa Alberto Fernandéz e Cristina Kirchner.
} 
em abril, segundo o EIL, $19 \%$ do total das empresas pesquisadas não operavam e $38 \%$ das empresas operavam com menos de $50 \%$ de sua capacidade produtiva (ARGENTINA, 2020a, não paginado, tradução nossa).

Tais indicadores constituíram-se os fundamentos das medidas estabelecidas pelo governo para sustentação dos postos de trabalho. As ações implementadas, que se referem aos postos formais de trabalho, são: 1) a ampliação do Programa de Recuperação Produtiva (REPRO) criado pela Lei Nacional 27.264 de 2016 e ampliado no período da pandemia. 2) alterações no regulamento de demissão, decreto que proíbe demissões e suspensão de trabalhadores por ausência ou outras causas relacionadas durante o período da pandemia (Decreto № 487, de 19/05/2020) (ARGENTINA, 2020c). Em decorrência da persistência da pandemia, essa medida aprovada em maio de 2020, foi estendida por mais 6o dias, tendo validade até 28/o9/2020 (Decreto № 624, de 29/o7/2020) (ARGENTINA, 2020d). O Decreto prevê, ainda, que as demissões ou suspensões realizadas de forma arbitraria não terão validade legal, mantendo assim o vínculo entre empregador e trabalhador; não há menção sobre como é a fiscalização do cumprimento do decreto. 3) Aos trabalhadores demitidos sem justa causa anteriormente ao decreto, é garantido o segurodesemprego, abonos de família e cobertura médica, cuja duração varia de acordo com o tempo de trabalho e contribuição para o sistema de seguridade social - Fundo Nacional de Emprego. 4) Complementarmente, como forma de proteção e manutenção da renda, os trabalhadores com 60 anos ou mais foram dispensados do trabalho com garantias do pagamento de salários.

O Programa de Recuperação Produtiva (REPRO) prevê um valor mensal fixo de até um salário-mínimo por um período de até 12 meses, destinado a completar o salário dos trabalhadores de empresas cujas receitas de vendas diminuíram por causa da emergência sanitária. Para acessar o benefício, as empresas devem comprovar a condição de crise, detalhando as ações que pretendem realizar para sua recuperação, comprometer-se a não demitir funcionários e manter a folha de pagamento total dos trabalhadores. Tal como pode ser visto na Tabela 2, 170 empresas acessaram o REPRO para sustentação de suas atividades depois da chegada da Covid-19. As empresas que mais buscaram o auxílio são do ramo de alimentos, metalúrgico e têxtil. Entre as cidades com maior número de REPROs, destacam-se Buenos Aires, Córdoba e Santa Fé, e das 193 empresas cadastradas, 126 têm até 100 trabalhadores (ARGENTINA, 2020e).

Tabela 2 - Programa de Recuperação Produtiva, janeiro a julho de 2020

\begin{tabular}{l|r|r|r}
\hline \multirow{2}{*}{ Itens } & \multicolumn{3}{|c}{ Benefícios } \\
\cline { 2 - 4 } & \multicolumn{1}{|c|}{ Total } & \multicolumn{1}{c|}{ antes da Covid } & \multicolumn{1}{c|}{ durante a Covid } \\
\hline Total de empresas & 193 & 23 & 170 \\
\hline Trabalhadores & 22.037 & 402 & 21.635 \\
\hline Valores mensais em pesos & $\$ 79.275 .500$ & $\$ 1.608 .000$ & $\$ 77.667 .500$ \\
\hline Valores totais em pesos & $\$ 237.826 .500$ & $\$ 4.824 .000$ & $\$ 233.002 .500$ \\
\hline Fonte: Argentina (2020e).
\end{tabular}


O governo anunciou, em 29/07, novas medidas - compreendendo a quarta etapa para assistência ao trabalho e produção. Não foi divulgado quando elas entrarão em vigor. Trata-se de repasse monetário aos trabalhadores, sendo: assistência de um valor complementar único de 1,5 salário mínimo - para aqueles setores considerados não críticos, e 2 salários mínimos para aqueles setores considerados críticos. Ainda, nesta nova etapa de assistência, as empresas que apresentarem variação no faturamento anual nominal entre o\% e $30 \%$ poderão acessar o crédito a taxa subsidiada.

Em que pese a importância das medidas anunciadas para a sustentabilidade dos empregos e da renda dos trabalhadores, elas não foram suficientes para manter os postos de trabalho, em especial nas pequenas e micro empresas. Em 2019, "[...] 9.251 empresas com até 10 pessoas fecharam as portas. Nos dois primeiros meses da pandemia (março e abril) 13.732 pequenas empresas foram encerradas (SOLO..., 2020, não paginado). Os setores mais afetados são hotelaria e gastronomia. Além do fechamento das empresas, os dados do Sistema Integrado de Seguridade Social do Ministério Nacional do Trabalho apontam para uma redução de $2,65 \%$ de trabalhadores registrados entre março e abril - um total de 320.000 pessoas que perderam seus empregos. Tais informações demonstram que, apesar dos esforços, as medidas anunciadas não foram suficientes para fazer frente aos impactos econômicos da pandemia (SOLO..., 2020).

No momento em que o Uruguai registrou seus primeiros casos do novo coronavírus (13/03) e decretou estado de emergência, seu PIB estava crescendo há dois anos a 2,7\% e a taxa de desemprego era de 8,9\% (2019). Em junho, essa taxa havia subido para 9,8\%, segundo o Instituto Nacional de Estatística (INE) (2020). Diferentemente do Brasil e da Argentina, o Uruguai não desenvolveu políticas diretas de sustentação do emprego, optando por encaminhar medidas que garantissem as condições de continuidade financeira das empresas, tais como: extensão do prazo dos pagamentos de empréstimos por seis meses; criação de linha de empréstimo estatal (Banco República) às empresas a juros mais baixos e com melhores condições contratuais; concessão de empréstimos de capital de giro de até 18 meses, com taxa subsidiada, a micro e pequenas empresas afetadas pela crise; lançamento de um programa de crédito para conceder liquidez a empresas individuais, mediante empréstimo de 12.000 pesos em maio e $\mathbf{1 2 . 0 0 0}$ pesos em junho, sem juros e pagamento em 24 parcelas iguais e consecutivas (anúncio em 4/05); diferimento do pagamento de impostos e contribuições, especialmente de empresas com até 10 funcionários da indústria e comércio; e redução do imposto sobre a propriedade para o setor agrícola (ORGANIZAÇÃO PARA A COOPERAÇÃO E DESENVOLVIMENTO ECONÔMICO, 2020).

O conjunto das medidas, no qual estão incluídas as de sustentação da renda, que no próximo tópico são descritas, foi financiado pelo Fundo Covid-19, valor que pode atingir US\$ 400 milhões (o,8\% do PIB). Este Fundo é financiado por recursos públicos, serviços de empresas estatais e por uma taxa de saúde de emergência Covid-19, aplicada aos salários e pensões de servidores públicos que ganhem mais de $\mathbf{1 2 0 . 0 0 0}$ pesos (alíquotas de $5 \%, 10 \%, 15 \%$ ou 20\%, dependendo do valor do salário). 
No Peru, no início da pandemia, a taxa de desemprego nacional era $5,1^{\%}$ ( $\mathbf{1}^{\mathrm{o}}$ trimestre/2020) e 7,8\% na região metropolitana de Lima (no trimestre móvel de janeiro/fevereiro/março de 2020). Ao final de 2019, 72,7\% dos trabalhadores peruanos eram informais (INSTITUTO NACIONAL DE ESTADÍSTICA E INFORMÁTICA, 2020a; 202ob). Essa foi uma das razões das estimativas de queda da economia peruana realizadas pelos organismos internacionais serem as piores do mundo.

No rol de medidas para proteger o emprego, o governo aproveitou programas já existentes e criou outros. O financiamento do conjunto das medidas foi a emissão de títulos do governo; no dia 16/o4, foram emitidos títulos no valor de US\$ 3 bilhões (ORGANIZAÇÃO PARA A COORPERAÇÃO E DESENVOLVIMENTO ECONÔMICO, 2020). Além disso, o Banco Central diminuiu a taxa de juros de 1,25\%aa (abril) para $0,25 \%$ aa (julho).

Para a manutenção do emprego dos trabalhadores de baixa renda, o governo passou a pagar $35 \%$ da folha de pagamento daqueles que ganham até 1.500 soles por mês. Mas deixou aberta a possibilidade de as empresas suspenderem os contratos de trabalho por no máximo de 90 dias, sem rescindi-los e sem pagar compensações aos trabalhadores. Em entrevista, a Ministra do Trabalho e Promoção do Emprego, Sylvia Cáceres, afirmou que a suspensão deve ser aplicada quando a empresa não puder realizar suas atividades de maneira remota e como último recurso, depois de esgotadas tentativas de acordo com os trabalhadores sobre redução da jornada e adiantamento das férias. A Ministra alertou, ainda, que a suspensão de contratos não pode ser usada para afastar líderes sindicais ${ }^{3}$

De forma indireta, o governo tem atuado para sustentar o emprego mediante o apoio às empresas, com destaque para três programas que auxiliam no acesso ao crédito, principalmente às micro e pequenas empresas. São eles: Fondo de Apoyo Empresarial para micro e pequenas empresas- FAE-Mype; Programa Reactiva Perú e Fondo Crecer. É importante lembrar que 90\% das empresas registradas no país são micro e pequenas empresas, e dentro dessa parcela, $95 \%$ são microempresas, que empregam $70 \%$ dos ocupados, a maior parte na informalidade (CUESTIONAN..., 2020).

O FAE-Mype, criado em 28/03/2020, é um fundo estatal para garantir crédito para capital de giro e refinanciamento de dívidas das micro e pequenas empresas. É outorgado por entidades financeiras e pelas cooperativas de poupança e crédito. Inicialmente, o fundo contava com 300 milhões de soles e garantia entre $30 \%$ e $70 \%$ do valor dos empréstimos (PERÚ, 2020c). O Programa Reactiva Perú, criado em 06/o4, é um fundo estatal que visa assegurar que as empresas cumpram com suas obrigações de curto prazo com trabalhadores e fornecedores. A garantia concedida pelo governo cobre entre $80 \%$ e $98 \%$ do valor do empréstimo. O valor recebido não pode ser utilizado para pagamento de atrasados fiscais e, durante a vigência dos empréstimos, a empresa não pode distribuir dividendos e lucros, exceção se aos trabalhadores. Como garantia, o governo disponibilizou o equivalente a $8 \%$ do PIB, sendo o mais ambicioso programa de garantias da história peruana (PERÚ, 2020d). Inicialmente, esse programa contava com 30 bilhões de soles.

3 Ver Ministra de Trabajo: "Suspensión perfecta de labores no aplicará para todas las empresas" (INSTITUTO DE INGENIEROS DE MINAS DEL PERÚ, 2020).

Argum., Vitória, v. 12, n. 3, p. 308-332, set./dez. 2020. | ISSN 2176-9575 
Em 27/o4, o FAE-Mype foi ampliado para 800 milhões de soles e a garantia do governo passou a 98\% (ORGANIZAÇÃO PARA A COORPERAÇÃO E DESENVOLVIMENTO ECONÔMICO, 2020). Em 10/o5, o Programa Reactiva Perú foi expandido para 6o bilhões de soles. Em 27/05, novas mudanças neste programa deram ênfase às micro e pequenas empresas, sendo aumentado o montante de empréstimos para elas. Os valores de empréstimos garantidos e realizados já ultrapassaram as metas. Até 12/o6, 143.409 empresas já haviam tomado empréstimos com garantias do FAE. O total de empréstimos estava em 1,7 bilhão de soles e a cobertura chegava a 1,15 bilhão de soles. Os quatro setores que mais buscaram o fundo foram: comércio, transportes, indústria manufatureira e hotéis/restaurantes (PERÚ, 202ob). O Programa Reactiva Perú, até 29/05, havia beneficiado 71.553 empresas, outorgando garantias de 21,6 bilhões de soles. As empresas dos setores do comércio, indústria manufatureira, atividades imobiliárias e transportes foram as que mais utilizaram o programa em termos de números de empresas e valores garantidos e emprestados (PERÚ, 2020a).

O Fondo Crecer, existente antes da pandemia, que visa facilitar o acesso das micro e pequenas e médias empresas ao crédito (CORPORACIÓN FINANCIERA DE DESARROLLO, 2020), teve seus recursos ampliados em 9o\% (em 01/2019, era de 1 bilhão de soles). As empresas beneficiárias têm vendas anuais até 2.300 UIT (Unidade Impositiva Tributária) e, no caso de exportadoras, com vendas anuais até 30 milhões de dólares (ORGANIZAÇÃO PARA A COORPERAÇÃO E DESENVOLVIMENTO ECONÔMICO, 2020). Entre 27/03 e 17/o4, houve um aumento de 52,73\% das micro, pequenas e médias empresas beneficiadas pelo fundo (GUTIÉRREZ, 2020).

Mesmo com todo esforço do governo, a produção nacional despencou e o desemprego no país disparou. De acordo com Instituto Nacional de Estadística e Informática (INEI) (2020a), o PIB caiu $17,3 \%$ no primeiro semestre, puxado pela queda de $30,2 \%$ no segundo trimestre, com destaque para a retração de $57,7 \%$ do investimento e 2,3 milhões de pessoas perderam seus empregos durante a pandemia na região metropolitana de Lima, o que equivale à metade dos trabalhadores da região. A taxa de desemprego subiu para 16,3\% (no trimestre móvel de abril/maio/junho de 2020) (INSTITUTO NACIONAL DE ESTADÍSTICA E INFORMÁTICA, 202od; 2020e). Diante disso, o governo lançou o Programa Arranca Perú, que consiste em um pacote de investimentos públicos em quatro grandes áreas: transportes, habitação, agricultura e trabalho (¿EN QUÉ CONSISTE..., 2020). Nos transportes, está previsto um investimento de 4 bilhões de soles e o objetivo é fazer manutenção nas redes vicinais; na área habitacional, é de 535 milhões de soles para construir 60 mil casas; na agricultura, 373 milhões de soles para fazer canais e manutenção de drenos; e na área do trabalho, 700 milhões de soles e a atuação se dará mediante um programa já existente, o Trabaja Perú, que tem como objetivo gerar empregos temporários destinados à população em idade para trabalhar, que se encontra em situação de pobreza, extrema pobreza ou afetada parcial ou integralmente por desastres naturais ou emergências (PERÚ, 2020e).

No México, apesar de a taxa de desemprego ser baixa, 2,94\% em março de 2020 e em queda desde o início do ano, a informalidade atingia 55,68\% dos trabalhadores. A crise econômica que se seguiu a epidemia, provocando a maior queda do PIB na história 
mexicana, $18,9 \%$ no segundo trimestre de 2020, em relação ao mesmo período de 2019 , segundo o Instituto Nacional de Estatística e Geografia (INEGI), poucas foram as novas ações do governo de Andrés Obrador para a sustentação do emprego, preferindo focalizar nos programas sociais existentes que já formavam a base das políticas de sua gestão. O governo vem promovendo drástico remanejamento do orçamento, priorizando os gastos com energia, infraestrutura e saúde, além dos programas sociais da Quarta Transformação do México $(4 \mathrm{~T})^{4}$, como forma de manter a renda e o emprego no país (CENTRO DE INVESTIGACIÓN ECONÓMICA Y PRESUPUESTARIA, 2020; MÉXICO, 2020). Conforme informa a Agência Efe (LAS CIFRAS..., 2020), o Instituto Mexicano de Previdência Social (IMSS) estima que 1,1 milhões de postos de trabalho formais foram eliminados desde o início da pandemia até o final de maio. Já em relação ao mercado informal, no mesmo período, o INEGI estima que 10,4 milhões de pessoas perderam suas ocupações.

Entre os programas de sustentação da atividade econômica destaca-se o Crédito a la Palabra, destinado a fornecer 2 milhões de empréstimos a micro, pequenas e médias empresas, inscritas no Instituto Mexicano de Previdência Social, no valor de 25 mil pesos cada, a taxa de juros subsidiada, para pagamento em 3 anos, com 3 meses de carência. Como condição de acesso a esse crédito, a empresa não pode ter reduzido salário nem demitido funcionários nos últimos 3 meses. Os recursos previstos para este programa são do banco de fomento Nacional Financiera e de impostos cobrados de grandes empresas devedoras da União. Todavia, aparentemente o programa mostra-se limitado, na medida em que o INEGI estima existirem mais de 4 milhões de microempresas no país.

As ações identificadas nos países pesquisados para sustentação do emprego durante a crise provocada pela Covid-19 podem ser agrupadas em quatro critérios: se houve ou não uma política dirigida aos trabalhadores formais; se os custos dessa política foram compartilhados entre empresas e governo; se houve ou não políticas voltadas para as pequenas e médias empresas; e se foram criadas novas políticas (novos programas) ou se foram utilizados e ampliados programas já existentes. O Brasil, a Argentina e o Peru atuaram diretamente na preservação do emprego formal e em todos eles houve compartilhamento do custo, muito embora, no caso do Brasil, a participação governamental ocorreu mediante o fundo do seguro desemprego. Em todos os países pesquisados foi dada especial atenção às pequenas e médias empresas mediante criação ou ampliação de linhas de crédito a juros mais baixos e com melhores condições de pagamento. Pelo menos no Brasil, essa preocupação não foi suficiente para garantir o sucesso desse programa. Dois países - Brasil e Peru - desenvolveram programas novos, sendo que os demais se utilizaram de programas e da estrutura de proteção já existentes.

Assim é que, no Brasil, Argentina e Peru, os programas implantados guardam semelhanças, pois os governos compartilham os custos com as empresas como forma de prestar assistência ao trabalho e à produção, através de financiamento subsidiado

\footnotetext{
4 Os programas sociais da 4T cresceram durante a Covid-19. As 3 transformações anteriores se referem a Independência em1821, a Reforma Liberal, de 1861 e a Revolução Mexicana de 1910 (LOS PROGRAMAS..., 2020).
} 
ou do repasse de recursos para complementar o pagamento dos trabalhadores. Destaca-se ainda, no Brasil, a redução da jornada de trabalho com salário complementado pelo seguro desemprego; na Argentina, a proibição de demissões, a dispensa dos trabalhadores com mais de 60 anos e o repasse de recursos para complementar os salários dos trabalhadores que sofressem perda; e, no Peru, a garantia do governo pagar $35 \%$ da folha de pagamento. As medidas instituídas ampararam o conjunto dos trabalhadores formais. Com relação aos informais, que constituem 54\% dos trabalhadores da América Latina (ORGANIZAÇÃO INTERNACIONAL DO TRABALHO, 2019), outras políticas precisaram ser desenvolvidas, tal como é descrita na parte a seguir relativa à renda. De qualquer maneira, ainda que essas medidas tenham sido insuficientes frente à realidade laboral provocada pela crise da Covid-19, os decretos aprovados, em especial na Argentina, que proíbe demissões, tornaram-se instrumentos passíveis de serem utilizados a favor dos trabalhadores.

Já no Uruguai, a estratégia foi exclusivamente centrada na manutenção das condições financeiras das empresas, mediante alteração das condições e prazos referentes a pagamento de empréstimos e criação de linha de empréstimo. Certamente um dos motivos que explicam essa postura é o fato de somente $25 \%$ de seus trabalhadores atuarem no mercado informal (ORGANIZAÇÃO INTERNACIONAL DO TRABALHO, 2019). De maneira geral, esse país tem um mercado laboral estruturado, o que o distingue dos demais países do grupo pesquisado. No caso do México, o governo optou por utilizar os programas sociais já existentes e não apresentou propostas específicas de sustentação de emprego. Ainda com relação a esse país, chama atenção o fato de os recursos necessários para a ampliação da cobertura terem como origem 0 remanejamento do orçamento.

\section{Políticas de garantia de renda}

No Brasil, a principal ação governamental no campo da sustentação de renda foi a criação do Auxílio Emergencial (AE). Em 29/o6, 64,1 milhões de pessoas haviam dele se beneficiado 5 . O AE é um benefício financeiro de $\mathrm{R} \$ 600,00$, podendo a mulher, caso provedora de família monoparental, receber duas parcelas, isto é, R\$ 1.200,00 concedido pelo governo federal e destinado aos trabalhadores informais, microempreendedores individuais, autônomos, contribuintes individuais ao Instituto Nacional de Seguro Social (INSS) e desempregados que pertençam à família cuja renda mensal per capita não ultrapasse meio salário mínimo ( $\$$ \$22,50) ou cuja renda familiar total seja de até três salários mínimos (R\$3.135,00). Em uma mesma família, no máximo duas pessoas podem receber esse auxílio. Inicialmente, o AE teria vigência por três meses (Lei no $\mathbf{1 3 . 9 8 2}$, de 2 de abril de 2020 (BRASIL, 2020c); Decreto № 10.316, de 7 de abril de 2020 (BRASIL, 2020a)), mas, em 30/o6, foi prorrogado por mais dois meses (Decreto $\mathrm{n}^{\mathbf{0}}$ 10.412, de 30 de junho de 2020 (BRASIL, 2020b). O AE é financiado por recursos do Tesouro Nacional, mediante emissão de títulos públicos.

\footnotetext{
$5 \mathrm{Na}$ tentativa de manter a renda, o governo também autorizou o saque de até um salário mínimo do Fundo de Garantia por Tempo de Serviço (FGTS) e a antecipação do auxílio doença concedido pelo Instituto Nacional do Seguro Social (INSS).
} 
Antes da pandemia, o Brasil tinha dois mecanismos de apoio à população de baixa renda: o Benefício de Prestação Continuada (BPC), dirigido às pessoas com 65 anos ou mais e aos deficientes cuja renda per capita familiar seja menor do que $25 \%$ do salário mínimo, de valor igual a 1 salário mínimo; e os benefícios do Programa Bolsa Família, dirigidos às famílias em condição de extrema pobreza (renda per capita de até R\$ 89,00 , recebendo o benefício fixo de $\mathrm{R} \$ 89,00$ ) e pobreza (renda per capita de até R\$ 178,oo, com direito a benefício de R $\$ 41$,oo por criança, adolescente ou gestante, até o limite de 5, chamado de benefício variável). Frente à situação emergencial, a Lei 13.982 definiu que o critério de acesso ao BPC pode ser ampliado a $1 / 2$ salário mínimo e que os beneficiários do Bolsa Família passariam a receber o $\mathrm{AE}^{6}$ enquanto ele estivesse em vigor. Em junho, quando 64,1 milhões estavam recebendo esse benefício, o que envolveu R\$90,8 bilhões, R\$40,9 bilhões corresponderam ao auxílio recebido pelos beneficiários do Bolsa Família, R $\$ 14$ bilhões aos que estavam inscritos no Cadastro Único $^{7}$ (pessoas e famílias de baixa renda) e R $\$ 35,9$ bilhões para os que se inscreveram no aplicativo ou site do AE.

Em 23/o7/2020, o IBGE (2020c) divulgou que 29,4 milhões de domicílios receberam, em junho, algum AE, o que representa $43 \%$ do total do país e abrange $49,4 \%$ da população brasileira (104,5 milhões de pessoas). Em termos de renda, $75,2 \%$ dos auxílios foram dirigidos aos estratos mais baixos da população brasileira. O segmento populacional mais favorecido foi o da primeira faixa (renda per capita de até R\$50,34), em que $83,5 \%$ (17,7 milhões de pessoas) receberam o auxílio. Para esses, a renda domiciliar per capita média passou de $\mathrm{R} \$ 7,15$ para $\mathrm{R} \$ 271,92$. Na segunda faixa de renda (renda per capita de $\mathrm{R} \$ 242,15$ ), o AE contemplou $86,1 \%$, o que corresponde a 18,2 milhões dos 21 milhões de pessoas que residiam nas casas onde pelo menos uma pessoa recebeu o auxílio. O impacto na faixa foi de $150 \%$, a renda média passou de $\mathrm{R} \$ 150,88$ para $\mathrm{R} \$ 377,22$.

No caso da Argentina, o contexto da pandemia, como era esperado, além de ocasionar empobrecimento social, aumentou a desigualdade em termos de níveis de renda. As agências internacionais destacam que, nos últimos anos (2010 - 2020), o governo argentino vem enfrentando dificuldades em combater seus altos níveis de pobreza e desemprego. O Observatório da Dívida Social da Universidade Católica da Argentina (ODSA) (OBSERVATORIO DE LA DEUDA SOCIAL ARGENTINA, 2020) aponta que a pobreza havia aumentado mais de 4,7\% em 2018 com relação ao ano anterior, chegando a 31,3\% no território nacional, e a $41,1 \%$ na região metropolitana de Buenos Aires até o final de 2018. Os dados referentes a 2019 demonstram que 40,8\% da

\footnotetext{
${ }^{6}$ Segundo o G1 (AUXÍlLIO..., 2020), do total de 108,4 milhões cadastros de pessoas, 106,3 milhões foram processados. Desses, foram considerados elegíveis 64,1 milhões de beneficiários, 1,3 milhão ficaram retidos para reanálise e os demais não foram considerados. Problemas no cadastramento e fraudes foram diversas vezes veiculadas na mídia.

7 O Cadastro Único para Programas Sociais do Governo Federal - também conhecido como Cadastro Único e Cad Único - objetiva identificar e caracterizar as famílias de baixa renda. São registrados no cadastro informações sobre as condições de moradia, saneamento, configuração familiar, situação da renda, escolaridade, entre outras. Estão no cadastro: famílias com renda mensal de até meio salário mínimo per capita, e famílias com renda mensal de até três salários mínimos; pessoas que vivem sozinhas também podem realizar o cadastro, basta atender aos critérios de renda. O cadastro serve de base para programas sociais como o Bolsa Família, o Minha Casa Minha Vida e mais recentemente para o Auxílio Emergencial (BRASIL, 2020f).
} 
população estavam em situação de pobreza, sendo estes os valores mais elevados desde a crise de 2001. Os relatórios do ODSA sinalizam para a pobreza no país como um problema crônico e acumulativo,

\begin{abstract}
Durante o período 2010-2019, os indicadores sociais mostram a persistência de altos níveis de pobreza e desigualdades estruturais, tanto de natureza econômico-ocupacional quanto sócio regional. As melhorias materiais relativas e a expansão das políticas de proteção social durante o último período não foram suficientes para reverter os níveis de pobreza estrutural. (OBSERVATORIO DE DEUDA SOCIAL ARGENTINA, 2020, não paginado, tradução nossa).
\end{abstract}

Para mitigar os impactos da pandemia sobre a população mais vulnerável, foi encaminhada uma série de medidas. Entre as ações identificadas, destacam-se: 1) a implementação da Renda Familiar de Emergência (RFE) (Decreto 310/2020 (ARGENTINA, 202ob), trata-se de uma transferência de renda, de 10.000 pesos argentinos, com previsão de cobertura de 3,6 milhões de famílias; 2) aumento nos valores para todos os beneficiários de programas já existentes, como o Auxílio Universal à Criança e o Auxílio à Gravidez para Proteção Social ${ }^{8}$, e pensões não contributivas. Os benefícios adicionais variam de US\$ 44 a US\$150, com o valor mais alto correspondente a pensões por invalidez; 3) ampliação do programa Emergência Alimentar e Nutricional (criado em 2019) em decorrência do empobrecimento e da insegurança alimentar das famílias mais vulneráveis.

A RFE, que inicialmente seria efetivada em parcela única, em abril, foi ampliada e novas parcelas foram pagas em junho e agosto. Os critérios para acessar este benefício são: estar desempregado ou em atividade laboral informal, ser inscrito nas categorias A e B do monotributo (trabalhadores independentes que contribuem para a previdência), ser assistido por programas sociais, receber o benefício universal de criança, ou universal de gravidez - estas não precisam se cadastrar para acessar o benefício da renda de emergência, pois foram incluídas como beneficiárias automaticamente quando da aprovação do Decreto 310/2020. Tais reforços foram implementados desde o início da pandemia (03/2020) e já atingem quase nove milhões de argentinos. Segundo o ODSA (2020), os repasses monetários contribuíram significativamente para incrementar a renda dos setores mais pobres e vulneráveis. Contudo, foram insuficientes, e não chegaram a todos que tiveram perdas em sua renda familiar. $\mathrm{O}$ benefício do cartão alimentação, que compõe o programa de segurança alimentar, teve efeitos positivos na proteção quanto ao risco de cair em uma situação mais extrema de privação de alimentos, assegurando os mínimos para a sobrevivência das famílias mais vulneráveis. No âmbito da região metropolitana, a mais afetada, 53,1\% dos domicílios estão assistidos por algum dos programas citados. Destes, 16,8\% estão incluídos no programa de assistência alimentar. O financiamento destas políticas, bem como de

\footnotetext{
${ }^{8}$ A Asignación Universal por Hijo para Protección Social (AUHPS) foi implementada na Argentina pelo Decreto $\mathrm{n}^{0}$ 1602/o9. O Auxílio Universal à Criança e o Auxílio à Gravidez para Proteção Social “[...] consiste de um benefício pago às crianças e adolescentes menores de 18 anos, residentes no país, ou incapacitados sem limite de idade, que sejam argentinos nativos ou naturalizados ou com residência legal no país mínima de 3 anos, que pertençam a famílias cujos pais se encontram desempregados, exerçam atividade doméstica ou exerçam atividade na economia informal [...] desempregados, não podem estar recebendo o seguro desemprego e, no caso dos dois últimos, a remuneração não pode ser superior a um salário mínimo" (MARQUES, 2013, p. 306).
} 
sustentação de emprego, foi garantido mediante emissão monetária e empréstimo realizado junto ao Fundo Financeiro para Desenvolvimento da Bacia do Prata (Fonplata). Destaca-se que o atual governo tem recebido apoio da população, com índice de mais de $80 \%$ de aprovação, especialmente pelas medidas adotadas no período da pandemia.

No Uruguai, diversas medidas foram tomadas para sustentar a renda dos trabalhadores e para apoiar os setores mais vulneráveis da população. Essas medidas constituem transferência de renda ou garantia de acesso a bens e serviços. Entre elas destacam-se: aumento de $100 \%$ dos valores do cartão Social do Uruguai (Tarjeta Uruguay Social) ${ }^{9}$ e do abono de família do Plan de Equidad $^{10}$; ampliação das vagas em abrigos para pessoas em situação de rua; entrega de cestas de alimentos; criação de ponto de concessão de janta; criação do seguro covid especial de desemprego e do seguro parcial que concedem subsídios para trabalhadores por conta própria por dois meses (6.80o pesos por mês para 10.000 trabalhadores); cesta de alimentos para familiares que recebem benefícios sociais; acesso gratuito à internet para 120.000 famílias. Além disso, as pessoas que alugam com a garantia do Escritório Geral de Contabilidade da Nação contam com um apoio direto do estado pelos $50 \%$ de seu aluguel e um subsídio pelos outros 50\%; em abril, as parcelas dos empréstimos hipotecários foram reduzidas para 50\% e o saldo repassado para o final do empréstimo, sem juros. As pessoas que não puderem pagar a taxa de abril (50\%) não foram multadas ou cobradas por 180 dias.

A essas iniciativas somaram-se a concessão de um auxílio doença a todos os assalariados do setor privado acima de 65 anos para garantir que cumprissem a quarentena (desde 25/03), a flexibilização das condições de acesso ao segurodesemprego, assegurando o direito aos trabalhadores mensais com contribuições entre 3 e 5 meses no último ano e diaristas com 75 a 149 dias (anúncio 8/o5). Ampliação do seguro-desemprego parcial (até 31/o7), pago aos trabalhadores que tiveram a atividade suspensa ou redução da jornada.

No Peru, a necessidade de políticas de sustentação de renda já vem de antes da pandemia $^{11}$. A taxa de pobreza e extrema pobreza, em 2019, de acordo com o INEI (2020c), era de $20,2 \%$ e $2,9 \%$, respectivamente. Os efeitos da crise evidenciaram mais

9Transferência monetária aos domicílios em situação de extrema vulnerabilidade socioeconômica. Seu objetivo é cobrir a população dos 60 mil domicílios mais vulneráveis. Os domicílios constituídos por adultos sem menores de 18 anos sob sua responsabilidade ou que tenham um dependente recebem $\$$ 1.201; havendo 2 menores, \$ 1823 ; 3, \$ 2318 ; e 4, \$ 3 230. Os 30 mil domicílios que se encontram em piores condições socioeconômicas recebem esses valores em dobro (URUGUAY, 2020).

${ }^{10}$ Também constitui uma transferência monetária, mas vinculado ao Instituto de Seguridad Nacional, responsável pelos benefícios previdenciários. O benefício é dirigido às crianças e adolescentes de domicílios em situação de vulnerabilidade ou internos em instituições. Para maiores detalhes e suas diferenças com relação à Tarjeta, ver Banco de Previsión Social (BPS) (2020).

${ }^{11}$ O Peru já possuía três programas de auxílio a renda para pobres e extremamente pobres, todos do Ministerio de Desarrollo e Inclusión Social (Mids). O Programa Contigo é um benefício de 300 soles pago a cada dois meses a pessoas com incapacidade severa e em situação de pobreza. O Programa Pensión 65 protege pessoas com mais de 65 anos que se encontram em situação de extrema pobreza, oferecendo um auxílio de 250 soles por bimestre. O Programa Juntos, de combate à pobreza, condiciona a transferência à presença escolar dos filhos, ao seu acompanhamento pelo centro de saúde e à realização dos exames de pré-natal pelas mulheres grávidas (PERÚ, 2020f). 
ainda essa necessidade. Assim, em 18/o3, o governo adotou uma medida para auxiliar financeiramente 3 milhões de famílias com uma quantia de 380 soles, criando o programa Yo me Quedo en Casa, destinado para lares em condições de pobreza ou extrema pobreza.

Em abril, o governo começou a pagar 720 soles para os trabalhadores da saúde e estendeu os programas de transferência de renda às famílias afetadas pela crise, criando o Bono Independiente e o Bono Rural - ambos no valor de 760 soles. Os outros requisitos de acesso são: a moradia deve se localizar em lugares com maior vulnerabilidade sanitária; a pessoa não pode ser beneficiária dos programas Juntos, Pensión 65 e Contigo; os membros familiares não devem ser trabalhadores vinculados do setor público ou privado nem possuírem cargos políticos (executivo ou legislativo); nenhum integrante da família deve receber mais que 1.200 soles ao mês. O Bono Rural é destinado a domicílios da zona rural em condições de pobreza ou extrema pobreza que não se beneficiam de outros apoios econômicos ou outros programas sociais (NUEVO..., 2020).

Mesmo com a criação desses três programas, muitas pessoas ficaram sem receber qualquer auxílio. Foi por isso que o governo criou o Bono Familiar Universal, de mesmo valor que os outros, para famílias consideradas pobres ou extremamente pobres que se enquadrem nos seguintes critérios: não ter sido beneficiado com os três programas anteriores; não ter nenhum integrante que receba mais de 3.000 soles por mês; e não ter nenhum membro da família vinculado ao setor público e/ou privado, exceto pensionistas. O benefício começou a ser pago em 11/5. Recebem também esse benefício os trabalhadores que se encontram com o contrato suspenso, com remuneração bruta de até 2.400 soles de empresas com até 100 funcionários. Ao final de julho, foi anunciada a ampliação da cobertura desses programas para os beneficiários dos programas pré-existentes à pandemia, isto é, Junto; Pensión 65 e Contigo (SEGUNDO..., 2020).

No México a política governamental para auxiliar as famílias a se protegerem e aderirem ao confinamento concentrou-se em antecipar os recebimentos bimensais, aos quais teriam direito os beneficiários dos 3 principais programas de transferência não condicionada de renda: Pensión para el Bienestar de los Adultos Mayores, Pensión para el Bienestar de las Personas con Discapacidad e Apoyo para el Bienestar de Niñas y Niños, Hijos de Madres Trabajadoras. Desde o início da crise sanitária, 270.425 novas pessoas aderiram a estes 3 programas. Além dessa medida, permitiu a prorrogação da entrega do IRPF de abril para junho; congelou a classificação das tarifas de consumo de eletricidade residencial (normalmente progressiva com o aumento no consumo); legou aos governos subnacionais o apoio financeiro a trabalhadores independentes e grupos vulneráveis; e aos trabalhadores com financiamento habitacional pelo Instituto Nacional de Habitação de Trabalhadores (INFONAVIT), que perderam emprego, o Instituto concedeu cobertura de 3 meses, podendo se estender por mais 3, sem custo ao trabalhador.

Todas essas medidas, não têm impacto expansionista no orçamento nacional. Apesar de organizações internacionais, como a CEPAL, alertarem que a austeridade não é

Argum., Vitória, v. 12, n. 3, p. 308-332, set./dez. 2020. | ISSN 2176-9575 
recomendada para a recuperação econômica, Andrés Obrador faz questão de manter rigorosamente a Lei Republicana de Austeridade, em vigor desde o início do mandato presidencial, preferindo o remanejamento de verbas orçamentárias.

O levantamento realizado das políticas para garantia da renda demonstra que em todos os países já existiam programas de transferência de renda dirigidos a certos segmentos da população, tais como crianças, idosos, gestantes, grupos familiares e indivíduos em vulnerabilidade, e tais programas foram ampliados ou mesmo flexibilizados em decorrência da Covid-19. Além disso, o Brasil, Peru, Argentina e México criaram programas de transferência direta de valores destinada à parcela da sociedade que está sob condições laborais de informalidade ou desenvolvendo atividade por conta própria. É relevante observar, no caso brasileiro, a criação do auxílio emergencial que, entre outros aspectos, reconhece as famílias monoparentais chefiadas por mulheres, concedendo, neste caso o dobro do valor do auxílio. No Uruguai, é no mínimo curioso que o governo tenha concedido aos maiores de 65 anos um auxílio doença, mesmo sem esses terem contraído o novo coronavírus. Na busca de preservar esse grupo de risco, foi ampliado, provisoriamente, o próprio conceito de auxílio doença. Talvez a garantia de uma renda, mesmo que focalizada, pudesse dar margem à defesa de sua manutenção futura, tal como em alguns propostas de Renda Básica ou Renda Garantida. Em todos os países, houve fortalecimento das políticas de segurança alimentar e, de uma maneira ou outra, houve ampliação do prazo para o pagamento de contas ou prestações.

\section{Considerações finais}

As manchetes dos jornais, revistas, artigos e estudos estatísticos apontam para um mesmo cenário quanto ao assunto pandemia da Covid-19 e contexto latino-americano - aumento da desigualdade social, queda do PIB, e acirramento de velhos problemas de ordem social. Como respostas as demandas urgentes da população latino-americana, os países precisaram compor um quadro de medidas que vem sendo complementado na medida que a pandemia avança. A CEPAL (2020) avalia que os investimentos realizados representam cerca do dobro dos custos anuais investidos nos programas de transferências de renda se comparado ao período anterior à crise da pandemia.

A pandemia alastrada demandou ações governamentais para enfrentamento das mazelas provocadas pela propagação da Covid-19 em, pelo menos, duas linhas - uma delas diz respeito a necessidade de estabelecer estratégias de prevenção da proliferação da contaminação da população, e cuidados em sanitários a fim de reestabelecer as condições de saúde da população afetada pelo vírus; a outra, se refere as estratégias de enfrentamento do impacto econômico que este cenário tem gerado, especialmente nas camadas mais populares da sociedade.

No grupo de países pesquisados, Brasil, Argentina, Uruguai, México e Peru, se identificam medidas em pelo menos três modalidades, não excludentes entre si medidas monetárias, fiscais e sociais. Para evitar o colapso do sistema econômico foram implantadas medidas monetárias e financeiras, medidas fiscais, medidas de preservação da capacidade produtiva e, para a atenção da população mais vulnerável,

Argum., Vitória, v. 12, n. 3, p. 308-332, set./dez. 2020. | ISSN 2176-9575 
reforçaram-se os programas sociais através da expansão dos sistemas de proteção social ou da criação de programas emergenciais com vista a sustentar pelo menos parte da renda perdida pelos trabalhadores informais ou pelos empreendimentos de pequeno e médio porte. Ao lado disso, alguns dos governos dos países estudados adotaram estratégias para garantir o emprego dos trabalhadores formais, partilhando o custo da manutenção dos salários.

Para todos os países, com exceção do Brasil, não foi possível obter informações que possibilitassem dimensionar a importância relativa dos auxílios concedidos. Não fossem essas medidas, o tamanho da crise nos países analisados teria sido certamente maior. A manutenção dessas políticas ou seu retorno ao padrão anterior está na dependência, desde logo, da superação da crise sanitária, mas também de que o aprofundamento da pobreza e desigualdade provocado pela crise não se torne duradouro. Para isso, de qualquer forma, será necessária a ação ativa do Estado na manutenção e na promoção de oportunidades de reinserções de pessoas e de pequenas e médias empresas. Sem esse apoio ativo, o resultado será, depois de passada a crise, uma sociedade mais excludente e uma economia mais oligopolizada.

\section{Referências}

ARGENTINA. Ministerio del Trabajo, Empelo y Seguridad Social. Situación e evolución del trabajo registrado. Buenos Aires, 5 junio 2020a. Disponível em: http://www.trabajo.gob.ar/downloads/estadisticas/reportelaboral/Reporte_Laboral_Ju nio_2020.pdf. Acesso em: 30 jul. 2020.

ARGENTINA. Decreto 310/2020. Ingreso Familiar de Emergencia (IFE). Buenos Aires, 202ob. Disponível em:

https://www.argentina.gob.ar/justicia/derechofacil/leysimple/emergencia-sanitariacovid-19-ingreso-familiar-de-emergencia\#titulo-1. Acesso em: 1 ago. 2020.

ARGENTINA. Ministerio da Justicia y Derechos Humanos. Decreto Legislativo no 487 de 19 de mayo de 2o2o. Prohibición de despidos y suspensiones. Buenos Aires, 2020c. Disponível em: http://servicios.infoleg.gob.ar/infolegInternet/anexos/3350oo339999/337677/norma.htm. Acesso em: 1 ago. 2020.

ARGENTINA. Ministerio da Justicia y Derechos Humanos. Decreto Legislativo no 624, de 29 de julio de 2020. Prohibición de despidos y suspensiones. Extensión. Buenos Aires, 2020d. Disponível em:

http://servicios.infoleg.gob.ar/infolegInternet/anexos/340ooo344999/340412/norma.htm. Acesso em: 1 ago. 2020.

ARGENTINA. Ministerio de Trabajo, Empleo y Seguridad Social. Secretaría de Trabajo - REPRO Aislamiento Sanitario. Relatorio. Buenos aires, 2020e. Disponível em: https://www.argentina.gob.ar/sites/default/files/copia_de_prensa_4_julio_1.pdf. Acesso em: 2 ago. 2020. 
AUXÍLIO Emergencial: Caixa paga $3^{\text {a }}$ parcela a 1,9 milhão de beneficiários do Bolsa Família com NIS final 9 nesta segunda. G1, Economia, São Paulo, 29 jun. 2020. Disponível em: https://g1.globo.com/economia/noticia/2020/o6/29/auxilioemergencial-caixa-paga-3a-parcela-a-19-milhao-de-beneficiarios-do-bolsa-familia-comnis-final-9-nesta-segunda.ghtml. Acesso em: 30 jul. 2020.

BANCO DE PREVISIÓN SOCIAL (BPS). Instituto de Seguridad Social. Plan de Equidad. Montevideo, 2020. Disponível em: https://www.bps.gub.uy/3540/plan-deequidad.html. Acesso em: 7 ago. 2020.

BANCO MUNDIAL. La Economía en Los Tiempos del Covid-19. Informe Semestral de la Región de América Latina y el Caribe, Abril de 2020.

BRASIL. Presidência da República. Decreto no1o.316, de 7 de abril de 2020. Regulamenta a Lei no $\mathbf{1 3 . 9 8 2}$, de 2 de abril de $\mathbf{2 0 2 0}$, que estabelece medidas excepcionais de proteção social a serem adotadas durante o período de enfrentamento da emergência de saúde pública de importância internacional decorrente do coronavírus (covid-19). Disponível em: http://www.planalto.gov.br/ccivil_03/_ato20192022/2020/decreto/d10316.htm. Acesso em: 1 ago. 2020.

BRASIL. Presidência da República. Decreto no 10.412, de 30 de junho de 2020. Altera o Decreto n⿳. 10.316 de 7 de abril de 2020, para prorrogar o período de pagamento do auxílio emergencial. Disponível em: http://www.in.gov.br/web/dou/-/decreto-n-10.412de-30-de-junho-de-2020-264424956. Acesso em: 1 ago. 2020.

BRASIL. Presidência da República. Lei Federal no 14.02o, de o6 de julho de 2020. Institui o Programa Emergencial de Manutenção do Emprego e da Renda; dispõe sobre medidas complementares para enfrentamento do estado de calamidade pública reconhecido pelo Decreto Legislativo no 6, de 20 de março de $\mathbf{2 0 2 0}$, e da emergência de saúde pública de importância internacional decorrente do coronavírus. Disponível em: http://www.planalto.gov.br/ccivil_03/_ato2019-2022/2020/lei/L14020.htm. Acesso em: 31 jul. 2020.

BRASIL. Presidência da República. Lei Federal no 13.982, de 2 de abril de 2020. Altera a Lei no 8.742, de 7 de dezembro de 1993, para dispor sobre parâmetros adicionais de caracterização da situação de vulnerabilidade social para fins de elegibilidade ao benefício de prestação continuada (BPC). Disponível em: http://www.planalto.gov.br/CCIVIL_03/_Ato2019-2022/2020/Lei/L13982.htm. Acesso em: 1 ago. 2020.

BRASIL. Congresso Nacional. Medida Provisória no 944, de 2ozo. Programa Emergencial de Suporte a Empregos. Disponível em: https://www.congressonacional.leg.br/materias/medidas-provisorias/-/mpv/141415. Acesso em: 31 jul. 2020.

BRASIL. Ministério da Cidadania. Cadastro Único. Brasília (DF), [2020]. 
COMISIÓN ECONÓMICA PARA AMÉRICA LATINA Y CARIBE (CEPAL). Enfrentar los efectos cada vez mayores del COVID-19 para una reactivación con igualdad: nuevas proyecciones. Informe Especial Covid-19 № 5, 15 de julho de 2020.

CENTRO DE INVESTIGACIÓN ECONÓMICA Y PRESUPUESTARIA (CIEP). Consideraciones de política fiscal ante el covid-19. Ciudad de México, 26 mar. 2020. Disponível em: http://ciep.mx/consideraciones-de-política-fiscal-ante-el-covid19. Acesso em: 18 jul. 2020.

CORPORACIÓN FINANCIERA DE DESARROLLO (COFIDE). Fondo Crecer. Lima, 2020. Disponível em: https://fondocrecer.cofide.com.pe/fondoCrecer/. Acesso em: 6 ago. 2020.

CONFEDERAÇÃO NACIONAL DOS TRABALHADORES NAS EMPRESAS DE CRÉDITO (CONTEC). MP 936/2020 - Balanço de empregos preservados pelo Programa Emergencial de Manutenção do Emprego e da Renda. Brasília (DF), 2020. Disponível em: https://contec.org.br/mp-9362020-balanco-de-empregospreservados-pelo-programa-emergencial-de-manutencao-do-emprego-e-da-renda/. Acesso em: 31 jul. 2020.

CONFEDERAÇÃO NACIONAL DO TRANSPORTE (CNT). Acesso ao crédito durante a pandemia: uma condição para a manutenção de empresas e empregos. Economia em Foco, 5 jun. 2020. Disponível em: https://static.poder36o.com.br/2020/o6/CNTcredito-empresas-pandemia-5jun2020.pdf. Acesso em: 31 jul. 2020.

CUESTIONAN programas de apoyo a las Mypes Reactiva Perú y FAE-Mype. El Búho, 3 maio 2020. Disponível em: https://elbuho.pe/2020/o5/cuestionan-programas-deapoyo-a-las-mypes-reactiva-peru-y-fae-mype/. Acesso em: 6 ago. 2020.

DEPARTAMENTO INTERSINDICAL DE ESTATÍSTICA E ESTUDOS ECONÔMICOS (DIEESE). Nota Técnica № 232. De o3 de abril de 2o2o. O Programa Emergencial de Manutenção do Emprego e da Renda diante dos impactos da Covid-19. São Paulo, 2020. Disponível em:

https://www.dieese.org.br/notatecnica/2020/notaTec232ProgramaEmergencialGovern o.pdf. Acesso em: 30 jul. 2020.

¿EN QUÉ CONSISTE "¿Arranca Perú”, el programa estatal que generará más de un millón de empleos? Rpp - notícias, 18 jun. 2020. Disponível em:

https://rpp.pe/economia/economia/en-que-consiste-arranca-peru-el-programa-quegenerara-mas-de-un-millon-de-empleos-coronavirus-en-peru-ministerio-de-viviendaministerio-de-trabajo-mef-arranca-peru-noticia-1273246. Acesso em: 6 ago. 2020.

FUNDO MONETARIO INTERNACIONAL (FMI). El Directorio Ejecutivo del FMI concluye la Consulta del Artículo IV con Perú correspondiente a 2019.

Comunicado de Prensa № 20/7, 14 de janeiro de 2020. Disponível em: https://www.imf.org/es/News/Articles/2020/o1/14/pr207-peru-imf-executive-boardconcludes-2019-article-iv-consultation. Acesso em: 2 ago. 2020. 
GUTIÉRREZ, Malena Miranda. 3,360 mipymes accedieron a recursos del Fondo Crecer. El Peruano, 20 abr. 2020. Disponível em: https://www.elperuano.pe/noticia-336omipymes-accedieron-a-recursos-del-fondo-crecer-94661.aspx. Acesso em: 6 ago. 2020.

INSTITUTO BRASILEIRO DE GEOGRAFIA E ESTATÍSTICA (IBGE). PNAD Contínua: taxa de desocupação é de $11,6 \%$ e taxa de subutilização é $23,5 \%$ no trimestre encerrado em fevereiro de 2020. Notícias, Brasília (DF), 31 mar. 2020a. Disponível em: https://agenciadenoticias.ibge.gov.br/agencia-sala-de-imprensa/2013-agencia-denoticias/releases/27259-pnad-continua-taxa-de-desocupacao-e-de-11-6-e-taxa-desubutilizacao-e-23-5-no-trimestre-encerrado-em-fevereiro-de2020\#: :text=Pr\%C3\%B3ximas\%2odivulga\% $\% \mathrm{C}_{3} \% \mathrm{~A}_{7} \% \mathrm{C}_{3} \% \mathrm{~B}_{5}$ es,PNAD\%2oCont $\% \mathrm{C}_{3} \%$ ADnua\%3A\%2otaxa\%2ode $\% 2$ odesocupa $\% \mathrm{C}_{3} \% \mathrm{~A}_{7} \% \mathrm{C}_{3} \% \mathrm{~A} 30 \% 2 \mathrm{O}$ $\% \mathrm{C}_{3} \% \mathrm{~A} 9 \% 2 \mathrm{Ode} \% 2 \mathrm{O11} \% 2 \mathrm{C} 6 \% 25$,encerrado\%2oem $\% 2$ ofevereiro\%2ode $\% 202020$. Acesso em: 30 jul. 2020.

INSTITUTO BRASILEIRO DE GEOGRAFIA E ESTATÍSTICA (IBGE). Pela primeira vez, menos da metade das pessoas em idade de trabalhar está desocupada. Notícias, Brasília (DF), 30 jun. 202ob. Disponível em:

https://agenciadenoticias.ibge.gov.br/agencia-noticias/2012-agencia-denoticias/noticias/28111-pela-primeira-vez-menos-da-metade-das-pessoas-em-idade-detrabalhar-esta-ocupada. Acesso em: 30 jul. 2020.

INSTITUTO BRASILEIRO DE GEOGRAFIA E ESTATÍSTICA (IBGE). Distribuição de auxílio emergencial alcança 29,4 milhões de domicílios em junho. Notícias, Brasília (DF), 23 jul. 2020c. Disponível em: https://agenciadenoticias.ibge.gov.br/agencianoticias/2012-agencia-de-noticias/noticias/28354-distribuicao-de-auxilio-emergencialalcanca-29-4-milhoes-de-domicilios-em-junho. Acesso em: 1 ago. 2020.

INSTITUTO NACIONAL DE ESTATÍSTICA (INE).Actividad Empleo y Desempleo. Disponível em: http://www.ine.gub.uy/web/guest/actividad-empleo-y-desempleo. Acesso em 01/o7/2020.

INSTITUTO NACIONAL DE ESTATÍSTICA E CENSOS (INDEC). Mercado de trabajo. Tasas e indicadores socioeconómicos (EPH). Informes Técnicos, Buenos Aires: Boletín técnico - Trabajo e ingresos, v. 4, n. 3, Primer trimestre 2020. Disponível em: https://www.indec.gob.ar/uploads/informesdeprensa/mercado_trabajo_eph_1trim2oA Fo3 1677 F.pdf. Acesso em: 1 ago. 2020.

INSTITUTO NACIONAL DE ESTADÍSTICA E INFORMÁTICA (INEI). Comportamiento de los indicadores de mercado laboral a nivel nacional - anual diciembre-enero 2019. Informe Técnico, Lima, n. 1, feb. 2020a. Disponível em: http://m.inei.gob.pe/media/MenuRecursivo/boletines/o1-informe-tecnicono1_empleo-nacional_oct-nov-dic2019.pdf. Acesso em: 6 ago. 2020.

INSTITUTO NACIONAL DE ESTADÍSTICA E INFORMÁTICA (INEI). Cuentas Nacionales. Lima, 202ob. Disponível em: http://www.inei.gob.pe/estadisticas/indicetematico/cuentas-nacionales-trimestrais-9747. Acesso em: 28 ago. 2020. 
INSTITUTO NACIONAL DE ESTADÍSTICA E INFORMÁTICA (INEI). Pobreza monetaria alcanzó al 20,2\% de la población en el año 2019. Nota de Imprensa, Lima, 2020c. Disponível em: http://m.inei.gob.pe/prensa/noticias/pobreza-monetariaalcanzo-al-202-de-la-poblacion-en-el-ano-2019-12196/. Acesso em: 6 ago. 2020.

INSTITUTO NACIONAL DE ESTADÍSTICA E INFORMÁTICA (INEI). Situación del Mercado Laboral em Lima Metropolitana - Trimestre móvil enero-febrero-marzo. Informe Técnico, Lima, n. 4, abr. 202od. Disponível em: http://m.inei.gob.pe/media/MenuRecursivo/boletines/o4-informe-tecnico04_mercado-laboral-ene-feb-mar-2020.pdf. Acesso em: 6 ago. 2020.

INSTITUTO NACIONAL DE ESTADÍSTICA E INFORMÁTICA (INEI). Situación del Mercado Laboral em Lima Metropolitana - Trimestre móvil abril-mayo-junio. Informe Técnico, Lima, n. 7, jul. 2020e. Disponível em: http://m.inei.gob.pe/media/MenuRecursivo/boletines/o7-informe-tecnicono7_mercado-laboral-abr.-May.-Jun.\%202020.pdf. Acesso em: 6 ago. 2020.

INSTITUTO DE INGENIEROS DE MINAS DEL PERÚ. Ministra de Trabajo: "Suspensión perfecta de labores no Aplicará para todas las empresas". Lima, abr. 2020. Disponível em: http://www.iimp.org.pe/actualidad/ministra-de-trabajo:$\%$ E2\%8o\%9Csuspension-perfecta-de-labores-no-aplicara-para-todas-lasempresas\%E2\%8o\%9D. Acesso em: 1 ago. 2020.

\section{INTERNATIONAL MONETARY FUND (IMF). World Economic Outlook Update.} June, 2020.

LAS CIFRAS de desempleo por la pandemia causan debate en México. Efe, México, 13 jun. 2020. Disponível em: http://www.efe.com/efe/america/economi/las-cifras-dedesempleo-por-la-pandemia-causan-debate-en-mexico/200ooo11-4270724. Acesso em: 28 ago. 2020.

LOS PROGRAMAS sociales de la $4 \mathrm{~T}$ crecen durante (y pese) al Covid-19. Forbes, Ciudad de México, 28 jul. 2020. Disponível em:https://www.forbes.com.mx/politicaprogramas-sociales-crecen-covid/. Acesso em: 8 ago. 2020.

MARQUES, Rosa Maria. Políticas de transferência de renda no Brasil e na Argentina. Revista de Economia Política, vol. 33, pp. 298-314, abril-junho/2013. Disponível em: https://www.scielo.br/pdf/rep/v33n2/ao6v33n2.pdf. Acesso em: 7 ago. 2020.

MARQUES, Rosa Maria; DEPIERI, Marcelo. Crise da Covid-19, estado e neoliberalismo. Natal: UFRN, no prelo.

MÉXICO. Câmara dos Deputados. Centro de Estudios de las Finanzas Públicas. Análisis de los Informes sobre las Finanzas Públicas y la Deuda Pública al Segundo Trimestre de 2020. Ciudad de México, 17 ago. 2020. Disponível em: 
http://www.cefp.gob.mx/publicaciones/documento/2020/cefpo302020.pdf. Acesso em: 18 jul. 2020.

NUEVO Padrón, Bono Independiente 76o soles: cómo y dónde ver si eres un beneficiario con tu DNI. El Bocón, 21 jun. 2020. Disponível em:

https://elbocon.pe/actualidad/coronavirus-peru-bono-independiente-padron-debeneficiarios-del-subsidio-economico-es-actualizado-por-el-mtpe-nndcnoticia/?ref=ebr. Acesso em: 3 ago. 2020.

OBSERVATORIO DE LA DEUDA SOCIAL ARGENTINA (ODSA). Avance del informe deudas sociales y desigualdades estructurales em la Argentina 2010-2019. Buenos Aires: Pontificia Universidad Católica Argentina (UCA), 2020. Disponível em: http://wadmin.uca.edu.ar/public/ckeditor/Observatorio\%2oDeuda\%2oSocial/Presenta ciones/2019/2019-Observatorio-Informe-Avance-5D.pdf. Acesso em: 1 ago. 2020.

ORGANIZAÇÃO INTERNACIONAL DO TRABALHO (OIT). Geração de empregos formais assalariados e transição para formalidade nos países em desenvolvimento. $O$ caso da América Latina. 2019. Disponível em: https://www.ilo.org/wcmsp5/groups/public/---ed_emp/--ifp_skills/documents/publication/wcms_729748.pdf. Acesso em: 25 ago. 2020.

ORGANIZAÇÃO PARA A COOPERAÇÃO E DESENVOLVIMENTO ECONÔMICO (OCDE). Combatendo o corona vírus (COVID-19). Contribuindo para um esforço global. 2020. Disponível em: https://www.oecd.org/coronavirus/country-policytracker/. Acesso em: 26 jun. 2020.

PERÚ. Ministerio de Economía y Finanzas. Estadísticas del FAE-Mype. Lima, 2020a. Disponível em: https://www.mef.gob.pe/contenidos/archivosdescarga/Estadi\%CC\%81sticas_FAE\%2oMYPE.pdf. Acesso em: 6 ago. 2020.

PERÚ. Ministerio de Economía y Finanzas. Estadísticas del Programa Reactiva. Lima, 202ob. Disponível em: https://www.mef.gob.pe/contenidos/archivosdescarga/Estadisticas_Reactiva_Peru.pdf. Acesso em: 6 ago. 2020.

PERÚ. Ministerio de Economía y Finanzas. FAE-Mype. Lima, 2020c. Disponível em: https://www.mef.gob.pe/es/que-es-el-fae-mype. Acesso em: 6 ago. 2020.

PERÚ. Ministerio de Economía y Finanzas. ¿Programa de Garantías? ¿Reactiva Perú? 202od. Disponível em: https://www.mef.gob.pe/es/que-es-reactiva-peru. Acesso em: 6 ago. 2020.

PERÚ. Ministerio Del Trabajo y Promoción del Empleo. Trabaja Perú. Lima, $2020 e$. Disponível em: https://www.trabajaperu.gob.pe/descripcion-del-programa/. Acesso em: 1 ago. 2020. 
PERÚ. Ministerio de Desarrollo e Inclusión Social. Orientación de trámites y servicios más visitados. Lima, 202of. Disponível em: https://www.gob.pe/midis. Acesso em: 3 ago. 2020.

PROGRAMA de Preservação do Emprego já evitou quase 11,7 milhões demissões. Notícias, Brasília (DF), 29 jun. 2020. Disponível em: https://www.gov.br/ptbr/noticias/trabalho-e-previdencia/202o/o6/programa-de-preservacao-do-emprego-jaevitou-quase-11-7-milhoes-demissoes . Acesso em: 8 ago. 2020.

SANTANDER. Análise de mercados - Argentina. Disponível em: https://santandertrade.com/es/portal/analizar-mercados/argentina/politica-yeconomia?\&actualiser_id_banque=oui\&id_banque=3\&memoriser_choix=memoriser\#p olitical. Acesso em: 17 jun. 2020.

SANT'ANA, J. Porque crédito do governo para pagar salários não está chegando às empresas. Gazeta do Povo, Brasília (DF), 14 maio 2020. Disponível em: https://www.gazetadopovo.com.br/republica/credito-do-governo-pagar-salariosempresas/. Acesso em: 31 jul. 2020.

SEGUNDO padrón, Bono Familiar Universal: fecha confirmada para el pago a beneficiários. El Bocón, 1o ago. 2020. Disponível em: https://elbocon.pe/trends/bonofamiliar-universal-fecha-confirmada-para-el-pago-a-beneficiarios-del-segundo-padronlink-para-ver-segundo-padron-primer-bono-76o-soles-bonos-de-estado-como-accederal-bono-universal-mtpe-martin-ruggiero-coronavirus-noticia/?ref=ebr\%2o. Acesso em: 6 ago. 2020.

SOLO en marzo y abril se perdieron 320 mil empleos registrados em el país. El Ciudadano, Rosario, 8 jul. 2020. Disponível em:

https://www.elciudadanoweb.com/solo-en-marzo-y-abril-se-perdieron-320-milempleos-registrados-en-el-pais-y-14-mil-en-la-provincia/. Acesso em: 30 jul. 2020.

URUGUAY. Ministerio de Desarrollo Social. Uruguay Tarjeta Social. Motevidéu, 2020. Disponível em: https://www.gub.uy/ministerio-desarrollo-social/politicas-ygestion/programas/tarjeta-uruguay-social. Acesso em: 7 ago. 2020.

WORLD BANK. Global Economic Prospects. Flagship Report - June 2020. 
Rosa Maria MARQUES Trabalhou na concepção, delineamento e interpretação dos dados; na redação do artigo e na aprovação da versão a ser publicada.

Graduada em Ciências Econômicas pela Universidade Federal do Rio Grande do Sul (1974). Mestre em Economia pela Pontifícia Universidade Católica de São Paulo (1985). Doutorado pela Fundação Getúlio Vargas - SP (1996). Pós-doutorado na Faculte de Sciences Economiques da Université Pierre Mendes France de Grenoble e na Universidad de Buenos Aires. Professora titular da PUC-SP. Foi presidente da Sociedade Brasileira de Economia Política e integrante da Comissão de Orçamento e Finanças do Conselho Nacional de Saúde. Foi presidente da Associação Brasileira de Economia da Saúde (ABrES) de 12/2012 a $12 / 2016$.

Solange BERWIG Trabalhou na concepção, delineamento e interpretação dos dados; na redação do artigo e na aprovação da versão a ser publicada.

Graduada em Serviço Social pela ULBRA (2010). Especialista em Políticas e Intervenção em Violência Infrafamiliar pela UNIPAMPA (2013). Mestre e Doutora em Serviço Social pela PUC/RS. Docente do curso de Serviço Social na UNIPAMPA (desde 2014), trabalhando na Graduação em Serviço Social; Pósgraduação: Especialização em Serviço Social e Direitos Humanos; Especialização em Políticas e Intervenção em Violência Intrafamiliar; Especialização em Serviço - Residência Multiprofissional em Saúde - tutoria do Serviço Social em Urgência e Emergência Hospitalar. Integrante do grupo de pesquisa: Trabalho, Formação Profissional em Serviço Social e Política Social na América Latina, Coordenadora de Estágio Supervisionado em Serviço Social 2019/2020.

Marcelo DEPIERI Trabalhou na concepção, delineamento e interpretação dos dados; na redação do artigo e na aprovação da versão a ser publicada.

Doutor em Ciências Sociais (2016) e mestre em Economia Política (2011) pela Pontifícia Universidade Católica de São Paulo. Realizou uma parte de seu doutorado na Universidade Autônoma de Barcelona (UAB) (2015). Possui graduação em Ciências Econômicas pela Universidade Presbiteriana Mackenzie (2008). Foi técnico do DIEESE durante Agosto de 2012 e Janeiro de 2015. Atualmente é professor de economia da Universidade Paulista (UNIP) e pesquisador no Núcleo de Estudos e Pesquisas Urbanas (NEPUR) e do Grupo de Pesquisas para o Desenvolvimento Humano (GPDH).

Marcel Guedes LEITE Trabalhou na concepção, delineamento e interpretação dos dados; na redação do artigo e na aprovação da versão a ser publicada.

Graduado em Economia pela Universidade de São Paulo (1980). Mestre em Economia de Empresas (1994) e doutor em Economia de Empresas pela Fundação Getulio Vargas - SP (2005). Atualmente é professor assistente doutor do departamento de Economia e do Programa de Estudos Pós Graduados em Economia Política da Pontifícia Universidade Católica de São Paulo. 